\title{
Single-Cut Single-Screw Capitate-Shortening Osteotomy for Kienbock's Disease
}

\author{
Gregory I. Bain, PhD, MBBS, FRACS, FA(Ortho)A ${ }^{1,2}$ Sathya Vamsi Krishna, MBBS, MS(Ortho) ${ }^{2}$ \\ Simon Bruce Murdoch MacLean, MBChB, FRCSEd (Tr\&Orth), PGDipCE ${ }^{3}$ Parth Agrawal, MBBS, MS (Ortho) ${ }^{2}$ \\ ${ }^{1}$ Department of Orthopedic Surgery and Trauma, Flinders University, \\ Adelaide, Australia \\ 2 Department of Orthopedic Surgery and Trauma, Flinders Medical \\ Center, Adelaide, Australia \\ ${ }^{3}$ Department of Orthopedic Surgery, Tauranga Hospital, Tauranga, \\ Address for correspondence Simon Bruce Murdoch MacLean, MBChB, \\ FRCSEd (Tr\&Orth), PGDipCE, Department of Orthopedic Surgery, \\ Tauranga Hospital, Cameron Road, Tauranga 3112, Bay of Plenty, \\ New Zealand (e-mail: Simonmaclean81@gmail.com).
} New Zealand

J Wrist Surg 2020;9:276-282.

\begin{abstract}
\section{Keywords}

- Kienbock's disease

- capitate shortening

- joint leveling

- capitate vascularity

- capitate osteotomy

Background Kienbock's disease, in spite of an uncertain natural history, is known to cause lunate compromise, leading to central column collapse, carpal instability, and degenerative arthritis of the wrist. Joint leveling procedures are performed in the early stages of Kienbock's disease to "unload" the lunate. Capitate shortening is the preferred procedure in Kienbock's patients with positive ulnar variance.

Description of Technique We describe the rationale and a simplified technique of capitate shortening in early Kienbock's disease. This is a single-cut osteotomy with single-screw stabilization.

Patients and Methods We have performed this technique in three cases. We present a case of a 26-year-old male who presented with a 1-year history of pain in his right wrist. Radiology performed demonstrated lunate sclerosis. Diagnostic arthroscopy revealed healthy articular surfaces. Single osteotomy capitate shortening was performed with an oscillating saw and fixed with a single cannulated compression screw. A shortening of $1.5 \mathrm{~mm}$ was obtained with this technique.

Results At 1-to 2-year follow-up, all three patients had considerable pain relief but did not have a complete resolution of pain. There was a significant improvement in function and grip strength. There have been no cases with infection, nonunion, avascular necrosis or a need for a salvage procedure.

Conclusion The simplified technique of capitate shortening is easy to perform, less traumatic to the capitate vascularity, and leads to good short-term functional results.
\end{abstract}

Just as the etiology of Kienbock's disease has remained controversial, so has the optimal treatment. Müller and Kienbock described the disease as one of overactivity from workplace activities, leading to "occupational lunatolmalacia." 1,2 The etiology is thought to be multifactorial, with both biological and mechanical triggers. ${ }^{3,4}$ Although the natural history is unclear, lunate compromise and fragmentation is

received

December 28, 2019

accepted

February 27, 2020

published online

May 1, 2020 known to cause central column collapse and proximal row instability. The late sequelais degeneration of the articular surfaces of the joint. ${ }^{5}$

There are three classification systems that define the osseous, chondral, and vascular components of the disease, which were described by Lichtman, Bain, and Schmitt, respectively. ${ }^{5-9}$ Lichtman and Bain developed a classification
Copyright $\odot 2020$ by Thieme Medical Publishers, Inc., 333 Seventh Avenue, New York, NY 10001, USA. Tel: $+1(212) 760-0888$
DOI https://doi.org/ 10.1055/s-0040-1709669. ISSN 2163-3916. 
system and algorithm that incorporates all these factors when assessing and planning surgical management. The aim of surgical treatment is to bypass or excise "nonfunctional articular surfaces," thereby reducing pain and maintaining functional wrist movement. ${ }^{6,10}$

The concept of an unloading procedure is a well-recognized surgical treatment. ${ }^{10}$ This procedure unloads the radiolunate articulation and also provides indirect revascularization due to regional hyperemia. ${ }^{11}$ Several techniques have been described for capitate-shortening osteotomy. Some of these techniques are technically challenging, risk violating the blood supply to the capitate, and not easily reproducible. We will review the osseous and vascular anatomy associated with capitate shortening with the aim to optimize the accuracy, safety, and reproducibility of the technique.

\section{Anatomy}

\section{Osseous}

The capitate is the largest of the carpal bones. It articulates proximally with the lunate and scaphoid and distally with the base of the third metacarpal and, variably, fourth metacarpal.

The capitate has three parts; the head, neck, and body. ${ }^{12}$ The head is the proximal articular aspect that has no ligamentous attachments. ${ }^{12,13}$ Distal to the head is a narrow neck covered in the periosteum. The body is distal to the neck. The dorsal and volar aspects of the body have ligamentous attachments. ${ }^{12,14-16}$ The volar aspect may have part of the adductor pollicis muscle insertion. ${ }^{14}$ The hamate articulates with a flat but elongated facet on the ulnar aspect of the capitate. ${ }^{14}$ The articular surfaces of these two joints are interrupted by the attachment sites for the deep trapezoidcapitate and capitate-hamate $(\mathrm{CH})$ ligaments. ${ }^{12}$

The proximal capitate articulation has been classified into three types: flat, spherical, and V-shaped. The flat capitate is associated with a single distal lunate facet type I lunate. The spherical type was associated with a concave articulation formed by the scaphoid and lunate articulations, with an indistinct border between the scaphoid and lunate facets.

The "V"-shaped capitate is associated with the presence of a type II lunate, with a large hamate facet, hamate ridge, capitate ridge, and a fourth carpometacarpal facet on the distal capitate). ${ }^{17}$ It is known that Kienbock's disease is more common if there is a type I lunate, which may be associated with a flatter proximal capitate articular surface. Capitate shortening is designed to unload the compromised lunate. $^{18-20}$

\section{Vascular Supply}

The vascularity of the lunate is known to be important in Kienbock's disease. We expect the vascularity of capitate to be important for the risk of postoperative nonunion and/or avascular necrosis (AVN). Most research has been directed to the arterial supply. ${ }^{21}$ Crock did some pioneering work on the venous drainage of the lunate. ${ }^{22}$ We have been able to apply this to the etiological concepts of Kienbock's disease. ${ }^{23,24}$

\section{Arterial}

An anatomical study by Vander Grend et $\mathrm{al}^{21}$ reported that the palmar blood supply was predominant. The palmar carpal branch provides vessels at the palmar ulnar border of the capitate neck. In addition, another large consistent branch from the deep palmar arch enters the palmar aspect of the distal capitate. Dorsally, the branches enter the capitate at the midwaist portion. There are no external vessels that enter the capitate head. Vander Grendet al reported that the capitate intraosseous blood supply has three types. In type 1 , the arterial supply was exclusively from the palmar vessels. In type 2, both the palmar and dorsal arteries supplied the waist and distal capitate, but the head was predominantly supplied by the palmar vessels. In type 3, the proximal pole is equally supplied by the palmar and dorsal vessels.

The intraosseous arterial blood supply assessed by Kadar et $\mathrm{al}^{25}$ using micro-CT reported the large arterial supply entering the capitate from the radial aspect of the neck.

\section{Venous}

Crock studied the arterial and venous systems and identified a subarticular venous plexus and a large single venous channel draining at the articular margin into a large single vascular channel ( - Fig. 1) ${ }^{22}$ Crock stated that a compromise to this venous plexus, through biological or mechanical factors, leading to venous stasis or venous hypertension, may play a part in the pathogenesis of AVN. ${ }^{22}$ We consider that it is also important to avoid compromise of this large vein during osteotomy for Kienbock's disease.

\section{Biomechanics of Capitate Shortening}

Werber et $\mathrm{al}^{26}$ described that a capitate shortening of 1.8 to $2 \mathrm{~mm}$ decreased the radiolunate pressure by 49 to $56 \%$ and that the load was redistributed to the radial and ulnar columns. ${ }^{27,28}$ Viola et $\mathrm{al}^{29}$ reported a $25 \%$ decrease after $2.9-\mathrm{mm}$ capitate shortening. Horii et al reported that a $4-\mathrm{mm}$ capitate shortening with $\mathrm{CH}$ fusion decreased the radiolunate pressure by $66 \%{ }^{30}$

\section{Fixation Options}

Various authors have described different techniques to stabilize the osteotomy, including plates, Kirschner (K) wires, staples, and screws (-Fig. 2). ${ }^{31-34}$

\section{Capitate Shortening}

Almquist ${ }^{19}$ recommended capitate shortening for Kienbock's disease in ulnar positive wrists. Various techniques have been reported and are presented in - Table 1. A summary of these results is that there have been 89 cases reported in the literature. The ranges of motion are similar to the preoperative values. However, the mean grip strength improved from 47 to $58 \%$ to 63 to $80 \%$ of the contralateral wrist. The mean visual analog scale score improved from a score of 6.0 to 8.2 to a score of 1.7 to 3.3. All cases united in 6 to 8 weeks. There was one case with irritation from the K-wire. The concepts of 

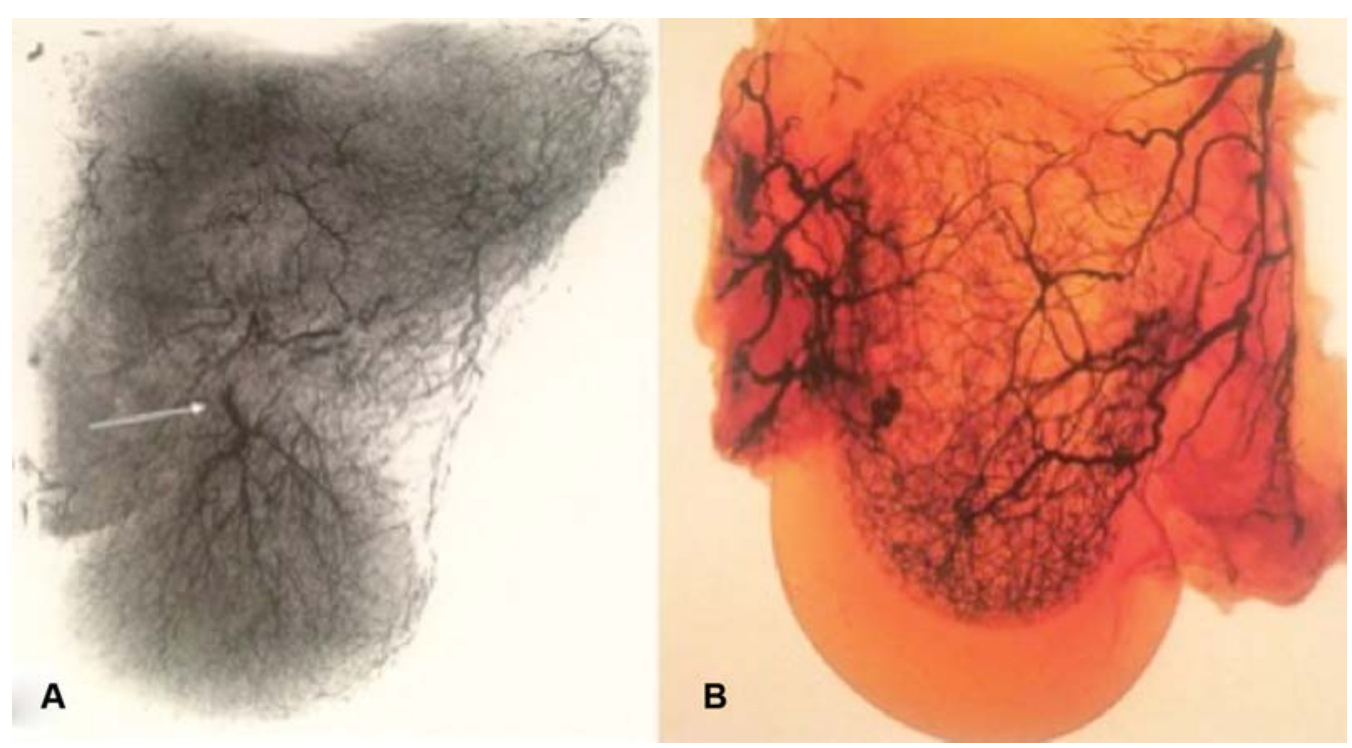

Fig. 1 Capitate vascularity. (A) The venous anatomy of the capitate. Note the single large vein draining the proximal capitate (white arrow). (B) The intraosseous arterial supply. (Reproduced with permission of Crock ${ }^{22}$.)

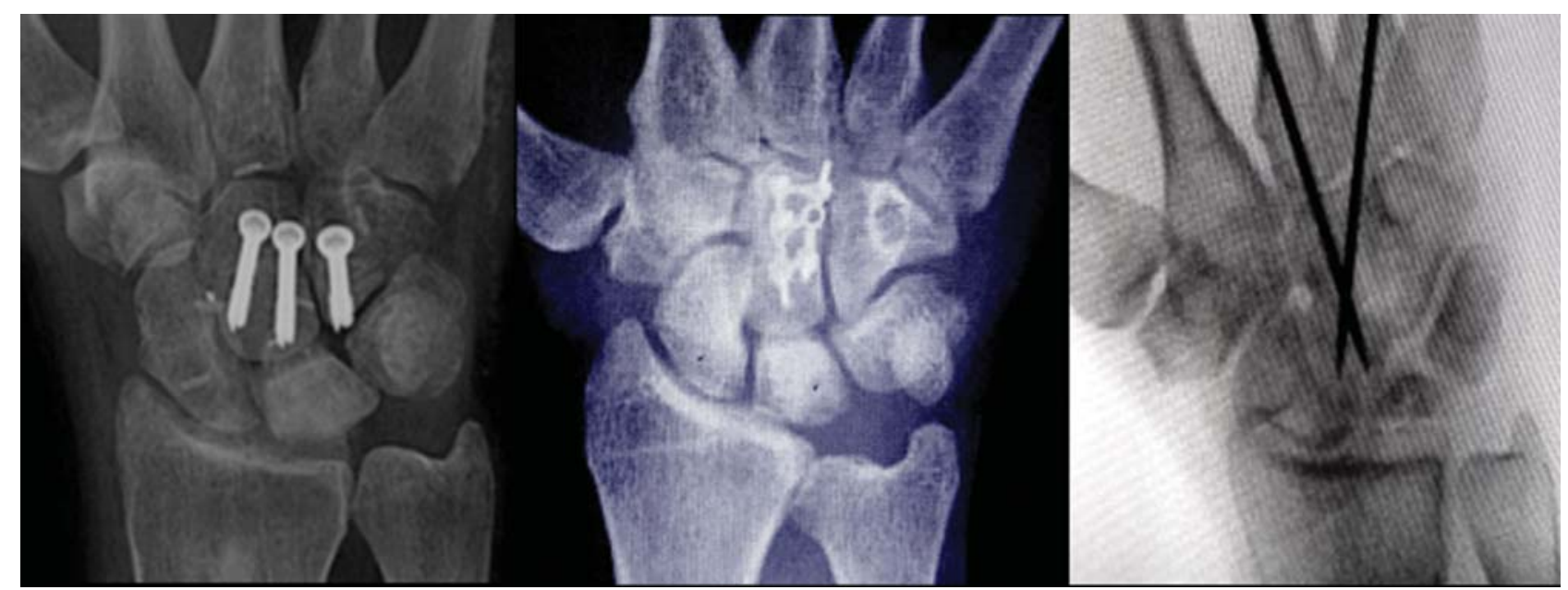

Fig. 2 Different methods of fixation for capitate-shortening osteotomy.

Table 1 Types of capitate osteotomy

\begin{tabular}{|c|c|}
\hline Author & Procedure \\
\hline Waitayawinyu et al $\mathrm{l}^{33}$ & $\begin{array}{l}\text { Capitate shortening with } \\
\text { VBG to the lunate }\end{array}$ \\
\hline Moritomoet al $^{18}$ & \multirow{3}{*}{$\begin{array}{l}\text { Capitate shortening in a } \\
\text { reverse } L \text { shape }\end{array}$} \\
\hline Citlak et $\mathrm{al}^{31}$ & \\
\hline Singer et $\mathrm{al}^{32}$ & \\
\hline Almquist $^{19}$ & \multirow[t]{2}{*}{ Capitate shortening } \\
\hline Gay et $\mathrm{al}^{34}$ & \\
\hline Viola et al ${ }^{29}$ & $\begin{array}{l}\text { Capitate shortening with } \\
\text { capitohamate fusion }\end{array}$ \\
\hline Graner et al ${ }^{35}$ & $\begin{array}{l}\text { Lunate excision, capitate } \\
\text { osteotomy with interposition } \\
\text { bone graft. }\end{array}$ \\
\hline
\end{tabular}

Abbreviation: VBG, vascularized bone grafting. partial capitate osteotomy and $\mathrm{CH}$ fusion were not obviously superior to a capitate osteotomy. However, patients with a lower Lichtman grade did have better outcomes. ${ }^{32-35}$

\section{Single-Cut Single-Screw Capitate- Shortening Osteotomy}

Based on the aforementioned anatomical and biomechanical factors, we propose a simplified technique of capitate osteotomy. We performed single-cut capitate osteotomy in three cases.

\section{Indication for Capitate Shortening}

The ideal scenario for capitate shortening is a patient who has a lunate that is intact (Lichtman and Bain grade B1) that should be protected. The wrist should have a neutral or positive ulnar variance. 


\section{Rationale for Single-Cut Osteotomy}

The publication by Werber et $\mathrm{al}^{26}$ has clearly demonstrated that the capitate shortening is very effective in reducing the radiolunate load. Shortening of $2 \mathrm{~mm}$, however, can result in a capitate that is not in contact with the lunate. The effect of this is to increase the load on the scaphotrapeziotrapezoid (STT) and triquetrohamate articulations. We believe that a 2-mm shortening is a lot for the midcarpal joint and likely to lead to a change in the mechanics more than is required. We believe that an osteotomy the width of the saw blade $(\sim 1 \mathrm{~mm})$ is adequate to unload the joint and reduce the excessive loading on the ulnar and radial columns.

\section{Rationale for the Site of Osteotomy}

Review of the capitate arterial ${ }^{21,36}$ and venous ${ }^{22}$ supply demonstrates that the proximal capitate head has a retrograde vascular supply, including vessels within the volar capsule. Placement of the osteotomy at the STT joint line position will preserve the volar capsular vessels.

\section{Rationale for Retrograde Fixation}

Antegrade fixation of the capitate involves hyperflexing the wrist and introducing the screw through the articular surface. Hyperflexion of the wrist places undue pressure on the fragile lunate and could cause it to fragment. The retrograde method can be performed without flexing or violating the joint.

\section{Rationale for Single Screw}

When performing a capitate osteotomy, there is a concern about the risk of nonunion or AVN. However, there have been no nonunions or AVN in almost 100 cases of capitate shortening published in the world literature. Therefore, if we preserve the soft tissue envelope, we expect that the osteotomy will heal with the stability of a well-placed single screw.

\section{Surgical Technique: “Retrograde” Single- Cut Single-Screw Capitate Osteotomy}

A 26-year old male with right wrist pain for 1 year presented to our clinic. He had midcarpal tenderness, flexion of 60 degrees, extension of 45 degrees, radial deviation of 30 degrees, ulnar deviation of 30 degrees. Grip strength was $28 \mathrm{~kg}$ bilaterally. Imaging demonstrated neutral ulnar variance and lunate sclerosis with coronal fracture without carpal collapse (-Figs. 3 and 4 ).

The treatment options and prognosis were considered and discussed with the patient. At wrist arthroscopy, the radiocarpal synovitis was debrided. The radiocarpal and midcarpal joint surfaces were pristine. The wrist was graded as B1 using the Lichtmanand Bain classification. It was decided to preserve and unload the lunate and perform a capitate shortening.

At wrist arthroscopy, the articular cartilage was assessed using the Bain and Begg classification. ${ }^{5}$ Any radiocarpal synovitis was debrided.

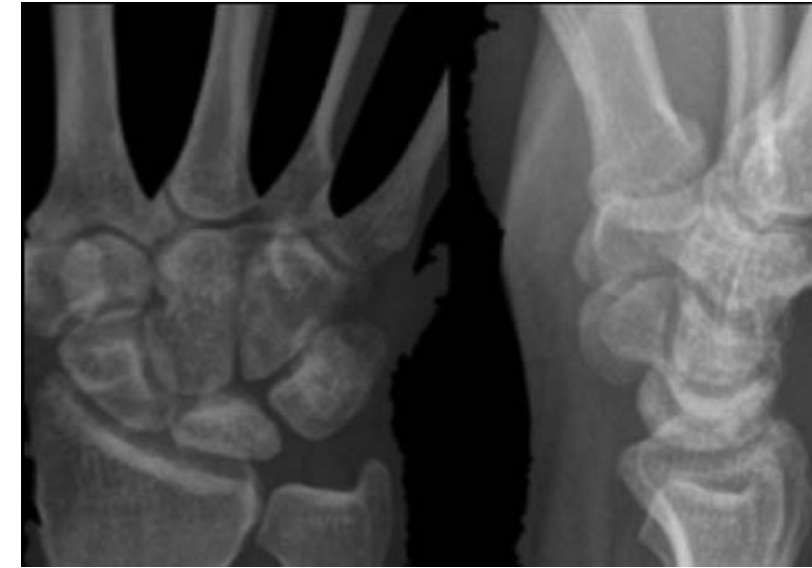

Fig. 3 Preoperative radiographs showing Kienbock's disease with lunate sclerosis.

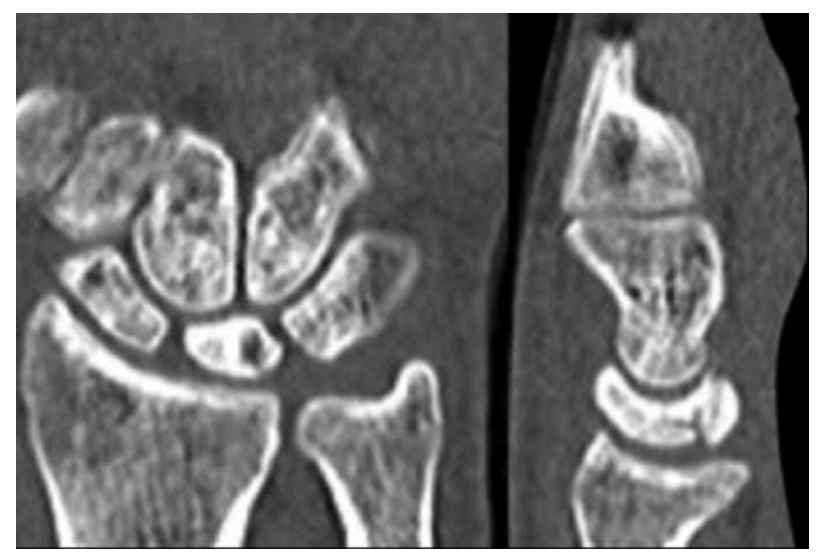

Fig. 4 Computed tomography images showing lunate sclerosis and a coronal fracture without carpal collapse.

\section{Surgical Technique: “Retrograde” Single- Cut Single-Screw Capitate Osteotomy}

We reviewed the plain radiographs to determine the correct alignment of the osteotomy. Our aim is to make the osteotomy parallel to the capitolunate articulation. This usually means that the osteotomy is slightly oblique ( $\mathbf{- F i g . 5}$ ).

The capitate is exposed through a dorsal approach. The extensor retinaculum does not need to be divided, as the capitate is distal to it. We predrill the osteotomy so that we try not to advance the K-wire into the unstable proximal capitate.

A small area of the third metacarpal base is removed with an osteotome to ensure the correct line of entry of the wire. A threaded guidewire is then passed down the capitate. On the anteroposterior plane, it is perpendicular to the proximal capitate joint surface. On the lateral projection, the wire is placed parallel to the dorsal cortex of the capitate. A cannulated drill is advanced over the wire and into the head of the capitate (-Fig. 6). We then remove the drill and the wire.

With a 6-mm-wide fine-tooth oscillating saw, a transverse capitate osteotomy is made distal to the midwaist (middle one-third) at the level of the STT joint (-Fig. 7). 


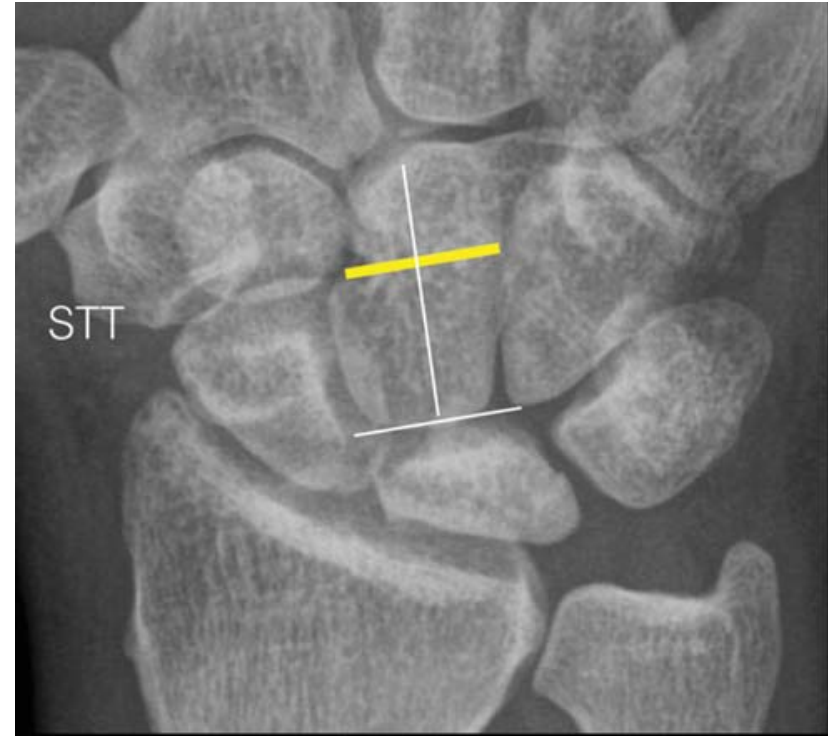

Fig. 5 The osteotomy is designed relative to the axis of the lunocapitate joint, at the level of the STT joint. STT, scaphotrapeziotrapezoid.

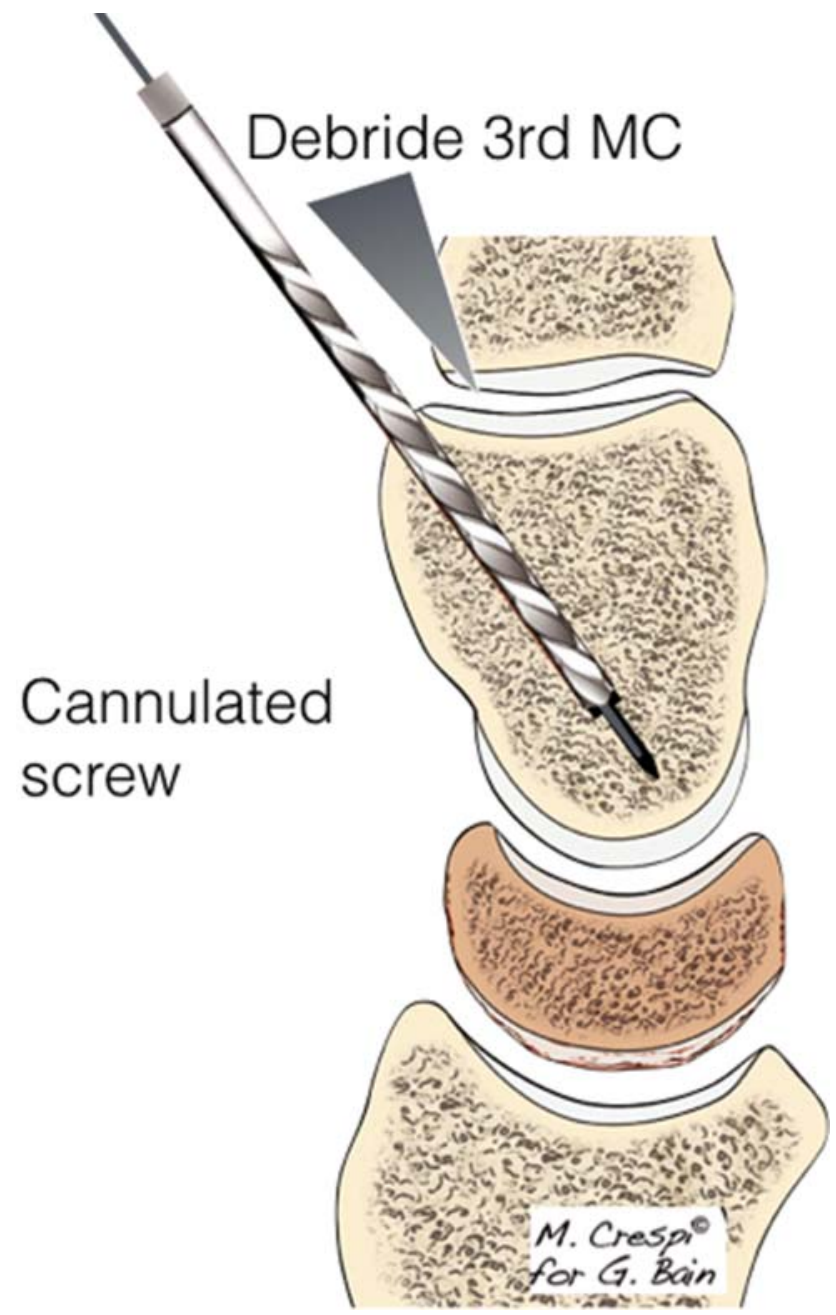

Fig. 6 A small area of the third MC base is removed with an osteotome to ensure the correct line of entry of the wire. A threaded guidewire is then passed down the capitate. On the lateral projection, the wire is placed parallel to the dorsal cortex of the capitate. A cannulated drill is advanced over the wire and into the head of the capitate. MC, metacarpal.

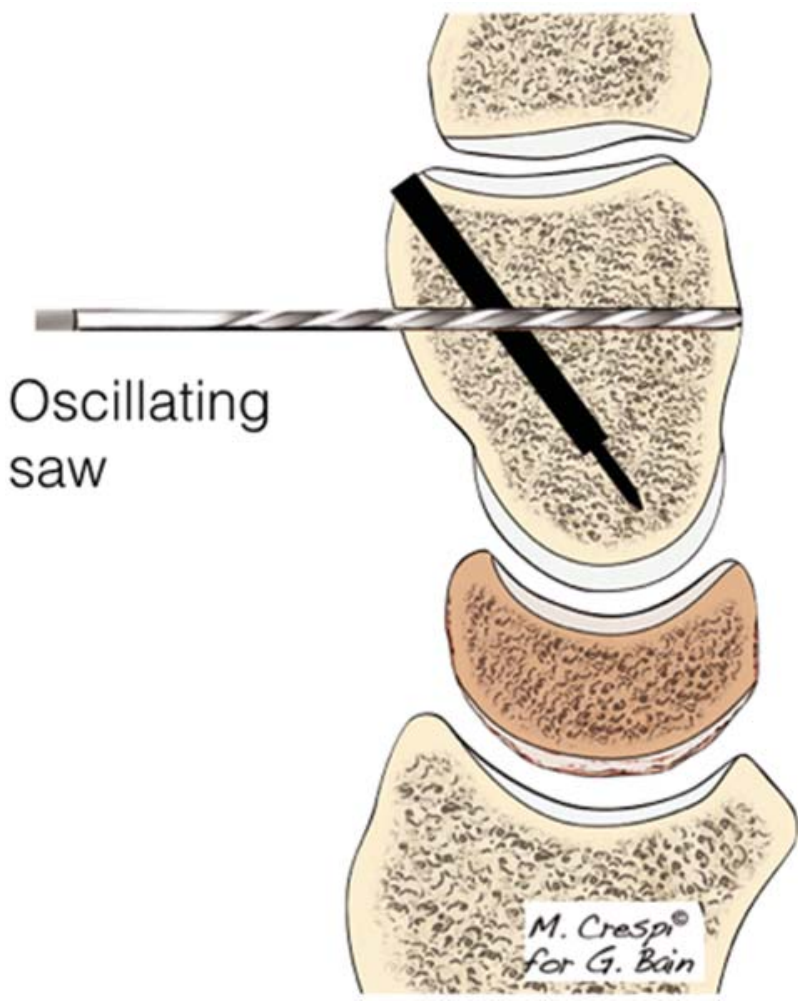

Fig. 7 With a 6-mm-wide fine-tooth oscillating saw, a transverse capitate osteotomy is made distal to the midwaist (middle one-third), at the level of the scaphotrapeziotrapezoid joint.

The osteotomy is not opened to preserve the soft tissue envelope. A sharp (5-mm) osteotome can be used to complete the osteotomy if necessary.

The K-wire is again inserted and then a single cannulated compression screw $(2.2 \mathrm{~mm})$ is advanced over the wire to compress the osteotomy (Medartis, Switzerland) ( - Fig. 8). The position is confirmed to be satisfactory with fluoroscopy. Capsule and skin are sutured in layers.

The osteotomy is inherently stable following fixation; therefore, the wrist is only immobilized with a volar splint for 2 weeks. The patient can then commence gentle range-ofmotion exercises. The patient can resume normal activity after 2 months. Radiographs at 6 months in our patient confirmed union with capitate shortening of $1.5 \mathrm{~mm}$ (-Fig. 9).

\section{Results}

All our three cases of capitate osteotomy have united. In line with previous publications, the patients did have some considerable pain relief but did not have a complete resolution of pain. There was an improvement in function and grip strength. There have been no cases with an infection, nonunion, AVN, or need for a salvage procedure.

\section{Discussion}

Panagis et $\mathrm{al}^{22}$ reported that the intraosseous vascularity of the capitate developed from both the palmar and dorsal aspects. Dorsally, two to four medium-sized vessels enter the 


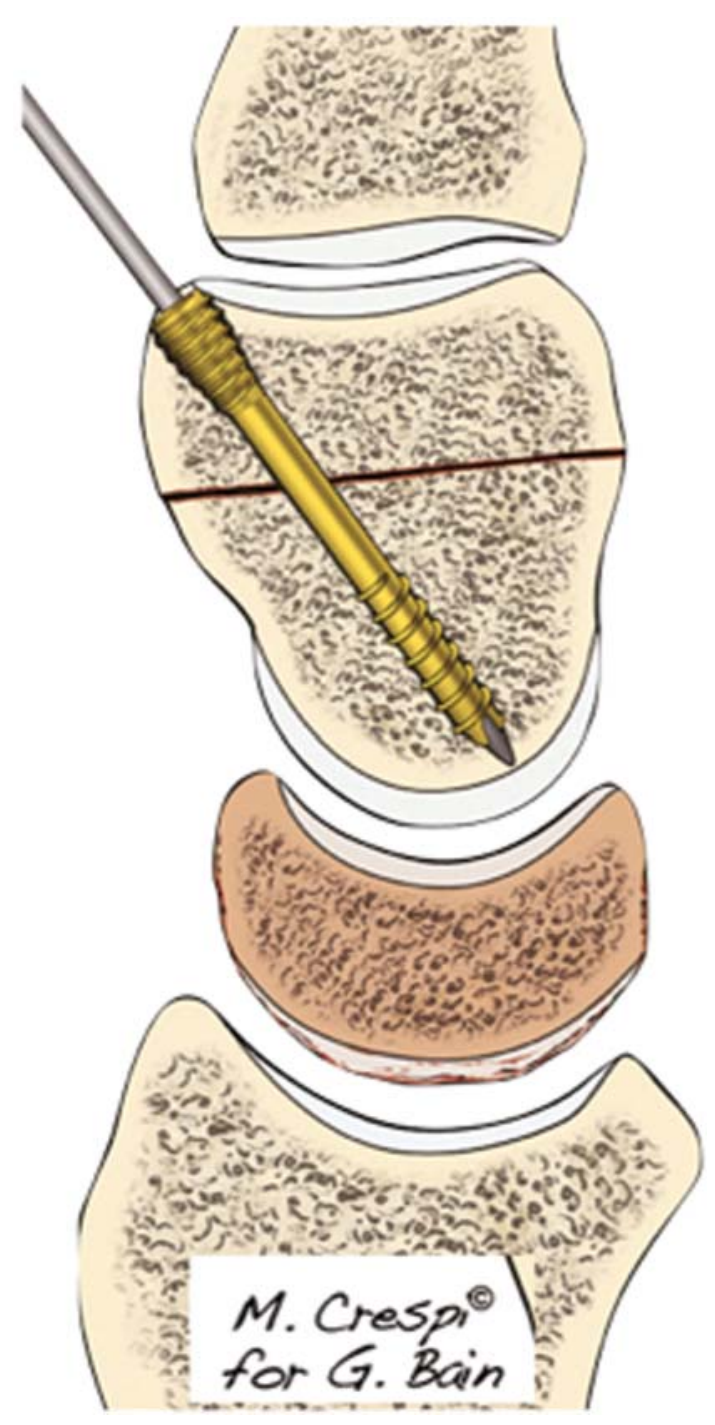

Fig. 8 The K-wire is again inserted and then a single cannulated compression screw $(2.2 \mathrm{~mm})$ is advanced over the wire to compress the osteotomy. distal two-thirds of the concavity of that surface. The vessels course palmarly, proximally, and slightly ulnarly, supplying the capitate body and head in $67 \%$ of the cases. Rarely, some vessels entered proximally in the neck. Palmarly, one to three medium-sized vessels enter slightly more proximally than the dorsal blood vessels but within the distal half of capitate. In the study by Panagiset al, however, the dorsal vessels predominated in most specimens. In $30 \%$ of specimens, there was anastomosis between the dorsal and volar networks.

The capitate proximal pole is supplied in a retrograde manner similar to the scaphoid. Cadaver studies have demonstrated vascular penetrations through the volar capsule at the articular margin. ${ }^{37}$ Hence, considering the unique vascularity, the osteotomy should be performed with precaution in theleast traumatic way as possible to the bone as well as volar carpal ligament to avoid the risk of AVN. It is recommended that the osteotomy is best performed no more proximal than the capitate waist. The technique reported in this article uses only a single cut, thereby decreasing the risk of compromising the capitate. We believe that $1 \mathrm{~mm}$ is enough to effectively unload the lunocapitate joint. Shortening more than this risks overloading the remaining midcarpal joints and the development of osteoarthritis, although this has not yet been proven.

There are few clinical studies on capitate shortening. Almquist reported a clinical series of $83 \%$ revascularization and healing of the lunate after capitate shortening with $\mathrm{CH}$ arthrodesis. $^{37}$

Overall, isolated capitate shortening, as described in this article, is easiest with a single cut and fixation with a single screw, which is adequate to stabilize the shortened capitate. This procedure has the advantage of shorter rehabilitation, and it can be combined with vascularization of the lunate if deemed necessary. Limitation of this procedure is that it increases the loads on the STT and TH joints, which may lead to degeneration later. ${ }^{30}$

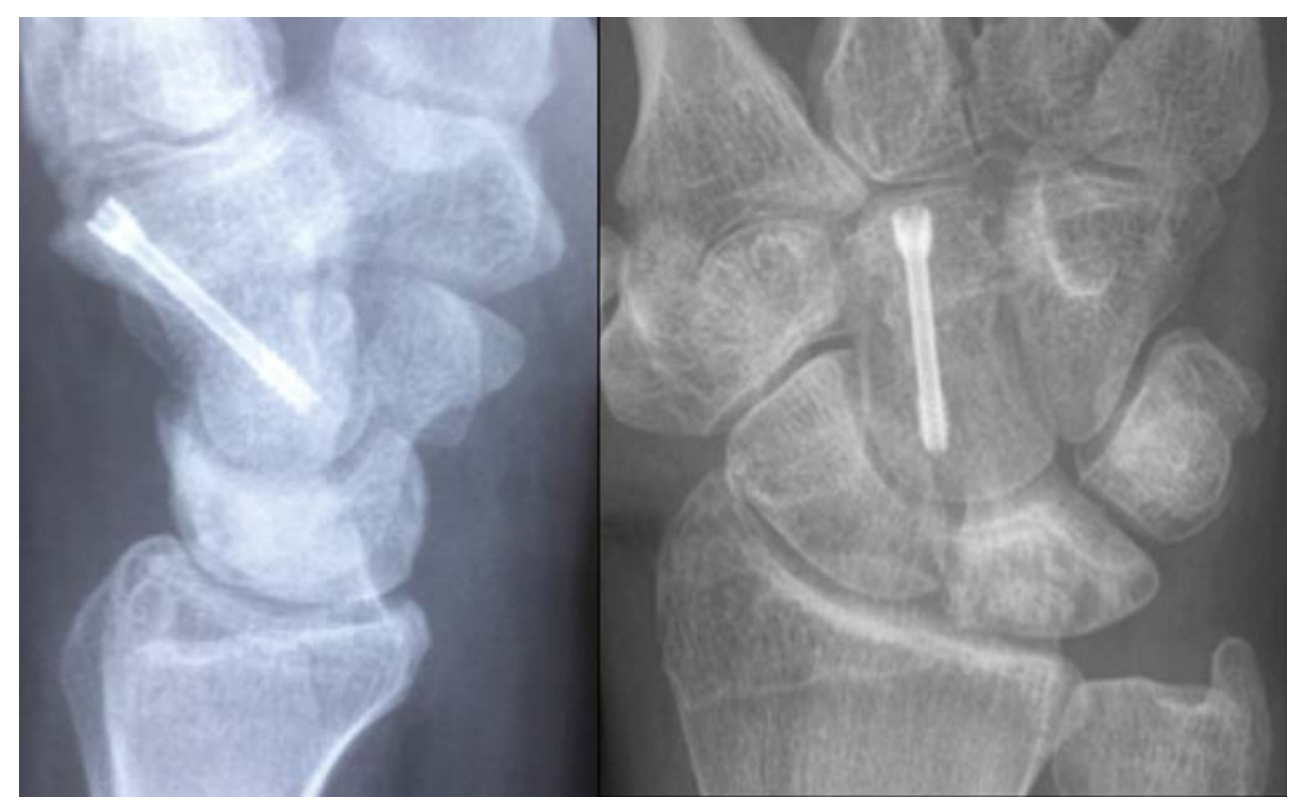

Fig. 9 Follow-up radiographs: united capitate osteotomy with no signs of avascular necrosis. No further collapse in the lunate was noted. 


\section{Note}

The study was performed at Flinders University, Adelaide, Australia.

\section{Conflict of Interest}

None declared.

\section{References}

1 Müller W. ÜberdieErweichung und Verdichtung des OsLunatum, eineTypischeErkrankung des Handgelenk. Beitr Klin Chir 1920; 119:664

2 Kienbock R. Concerning traumatic malacia of the lunate and its consequences: joint degeneration and compression. Fortsch Geb 1910;16:77-103

3 Bain GI, MacLean SBM, Yeo CJ, Perilli E, Lichtman DM. The etiology and pathogenesis of Kienböckdisease. J Wrist Surg 2016;5(04): 248-254

4 Lichtman DM, Pientka WF II, Bain GI. Kienböckdisease: a new algorithm for the 21st century. J Wrist Surg 2017;6(01):2-10

5 Bain GI, Begg M. Arthroscopic assessment and classification of Kienbock's disease. Tech Hand Up ExtremSurg 2006;10(01):8-13

6 Lichtman DM, Mack GR, MacDonald RI, Gunther SF, Wilson JN. Kienböck's disease: the role of silicone replacement arthroplasty. J Bone Joint Surg Am 1977;59(07):899-908

7 Schmitt R, Heinze A, Fellner F, Obletter N, Strühn R, Bautz W. Imaging and staging of avascular osteonecroses at the wrist and hand. Eur J Radiol 1997;25(02):92-103

8 Schmitt R, Lanz U. Diagnostic imaging of the hand. Available at: http://inis.iaea.org/Search/search.aspx?orig_q=RN:39115039. Accessed May 1, 2018

9 Bain GI, MacLean SBM, Tse WL, Ho PC, Lichtman DM. Kienböckdisease and arthroscopy: assessment, classification, and treatment. J Wrist Surg 2016;5(04):255-260

10 Bain GI, Durrant A. An articular-based approach to Kienbock avascular necrosis of the lunate. Tech Hand Up Extrem Surg 2011;15(01):41-47

11 Nakamura R, Watanabe K, Tsunoda K, Miura T. Radial osteotomy for Kienböck's disease evaluated by magnetic resonance imaging. 24 cases followed for 1-3 years. Acta Orthop Scand 1993;64(02): 207-211

12 Berger RA. The anatomy and basic biomechanics of the wrist joint. J Hand Ther 1996;9(02):84-93

13 Berger RA. The ligaments of the wrist. A current overview of anatomy with considerations of their potential functions. Hand Clin 1997;13(01):63-82

14 Bogumill G. Anatomy of the Wrist. Philadelphia, PA: WB Saunders; 1988

15 Feipel V, Rooze M. The capsular ligaments of the wrist: morphology, morphometry and clinical applications. Surg Radiol Anat 1999;21(03):175-180

16 Taleisni k J. The ligaments of the wrist. J Hand Surg Am 1976;1 (02):110-118

17 Yazaki N, Burns ST, Morris RP, Andersen CR, Patterson RM, Viegas SF. Variations of capitate morphology in the wrist. J Hand Surg Am 2008;33(05):660-666

18 Moritomo H, Murase T, Yoshikawa H. Operative technique of a new decompression procedure for Kienböck disease: partial capitate shortening. Tech Hand Up ExtremSurg 2004;8(02): 110-115
19 Almquist EE. Kienbock's disease. Clin Orthop Relat Res 1986; (202):68-78

20 Effect on force transmission across the carpus in procedures used to treat Kienböck's disease. J Hand Surg Am 1990;15(03):393-400

21 Vander Grend R, Dell PC, Glowczewskie F, Leslie B, Ruby LK. Intraosseous blood supply of the capitate and its correlation with aseptic necrosis. J Hand Surg Am 1984;9(05):677-683

22 Crock HV. Atlas of Vascular Anatomy of the Skeleton and Spinal Cord. London: Martin Dunitz; 1996:175-183

23 Bain GI, MacLean SBM, Yeo CJ, Perilli E, Lichtman DM. Erratum: the etiology and pathogenesis of Kienböck disease.. J Wrist Surg 2016;5(04):e1

24 Lichtman DM, Bain GI, eds. The etiology of Kienbock's disease. In: Kienböck's Disease: Advances in Diagnosis and Treatment. Basel, Switzerland: Springer; 2016

25 Kadar A, Morsy M, Sur Y-J, Laungani AT, Akdag O, Moran SL. The vascular anatomy of the capitate: new discoveries using microcomputed tomography imaging. J Hand Surg Am 2017;42(02): 78-86

26 Werber KD, Schmelz R, Peimer CA, Wagenpfeil S, Machens HG, Lohmeyer JA. Biomechanical effect of isolated capitate shortening in Kienbock's disease: an anatomical study. J Hand SurgEur Vol 2013;38(05):500-507

27 Werner FW, Palmer AK. Biomechanical evaluation of operative procedures to treat Kienböck's disease. Hand Clin 1993;9(03): 431-443

28 An KN. The effect of force transmission on the carpus after procedures used to treat Kienböck's disease. Hand Clin 1993;9 (03):445-454

29 Viola RW, Kiser PK, Bach AW, Hanel DP, Tencer AF. Biomechanical analysis of capitate shortening with capitate hamate fusion in the treatment of Kienböck's disease. J Hand Surg Am 1998;23(03): 395-401

30 Horii E, Garcia-Elias M, Bishop AT, Cooney WP, Linscheid RL, Chao EY. Effect on force transmission across the carpus in procedures used to treat Kienböck's disease. J Hand Surg Am 1990;15(03): 393-400

31 Citlak A, Akgun U, Bulut T, Tahta M, Dirim Mete B, Sener M. Partial capitate shortening for Kienböck's disease. J Hand Surg Eur 2015; 40(09):957-960

32 Singer MS, Essawy OM, Farag HEM. Early results of partial capitate shortening osteotomy in management of Kienböck disease. Curr Orthop Pract 2017;28:297-302

33 Waitayawinyu T, Chin SH, Luria S, Trumble TE. Capitate shortening osteotomy with vascularized bone grafting for the treatment of Kienböck's disease in the ulnar positive wrist. J Hand Surg Am 2008;33(08):1267-1273

34 Gay AM, Parratte S, Glard Y, Mutaftschiev N, Legre R. Isolated capitate shortening osteotomy for the early stage of Kienböck disease with neutral ulnar variance. Plast Reconstr Surg 2009;124 (02):560-566

35 Graner O, Lopes EI, Carvalho BC, Atlas S. Arthrodesis of the carpal bones in the treatment of Kienböck's disease, painful ununited fractures of the navicular and lunate bones with avascular necrosis, and old fracture-dislocations of carpal bones. J Bone Joint Surg Am 1966;48(04):767-774

36 Panagis JS, Gelberman RH, Taleisnik J, Baumgaertner M. The arterial anatomy of the human carpus. Part II: the intraosseous vascularity. J Hand Surg Am 1983;8(04):375-382

37 Almquist EE. Capitate shortening in the treatment of Kienböck's disease. Hand Clin 1993;9(03):505-512 